\title{
Quantification and comparison of 4D Flow MRI derived wall shear stress and MRE derived wall shear stiffness of abdominal aorta
}

\author{
Venkata Sita Priyanka Illapani ${ }^{5,1^{*}}$, Julio Garcia ${ }^{2}$, Ria Mazumder ${ }^{4,1}$, Richard D White ${ }^{4,3}$, Michael Markl ${ }^{2,6}$, \\ Arunark Kolipaka ${ }^{1,3}$
}

From 19th Annual SCMR Scientific Sessions

Los Angeles, CA, USA. 27-30 January 2016

\section{Background}

Aortic wall shear stiffness (AWS) and wall shear stress (WSS) are important indicators of pathological changes in the abdominal aorta. Previous studies have shown that AWS increases with diseases such as hypertension and atherosclerosis while WSS decreases ${ }^{1,2}$ with these diseases. Therefore, early detection of AWS and WSS could significantly impact timely treatment of these pathological conditions. Non-invasive estimation of AWS and WSS became feasible after the recent advent of phase contrast MRI based magnetic resonance elastography $(\mathrm{MRE})^{3}$ and $4 \mathrm{D}$ flow $\mathrm{MRI}^{4}$ respectively. We hypothesize that investigating the relationship between AWS and WSS may provide additional information to assist in diagnosis of aortic diseases. Therefore, in this study, we use both MRE and 4D flow MRI to estimate and establish the correlation between AWS and WSS in normal human subjects.

\section{Methods}

MRI was performed on 20 volunteers in a 3T Siemens scanner (Tim-Trio, Siemens Healthcare, Germany). Imaging parameters included: $M R E$ : TE/TR $=9.52 / 14.28$ $\mathrm{ms}$; slice thickness $=6 \mathrm{~mm}$; number of slices $=3$; acquisition matrix $=128 \times 64 ; \alpha=25^{\circ}$; Field of view $(\mathrm{FOV})=40 \mathrm{~cm}^{2}$; number of segments $=6$ to 8 and $\mathrm{a}$ motion encoding gradient $(\mathrm{MEG})=120 \mathrm{~Hz} ; \mathbf{4 D} \boldsymbol{P C}$ MRI TE $/ \mathrm{TR}=2.1 / 5.1 \mathrm{~ms}$; velocity encoding $=150 \mathrm{~cm} / \mathrm{s}$; flip angle $=7^{\circ}$, acquisition matrix $=192 \times 120 \times 26$; temporal resolution $=40.8 \mathrm{~ms}$, spatial resolution $=1.7 \times$ $2 \times 2.2 \mathrm{~mm}^{3}$. Images were processed in MRElab (Mayo

${ }^{5}$ Department of Biomedical Engineering, The Ohio State University, Columbus, OH, USA

Full list of author information is available at the end of the article
Clinic, Rochester, MN) to estimate end-systolic (ES) AWS while Ensight (CEI, Apex, NC) and custom built tool programmed in Matlab ${ }^{5}$ was used to measure WSS. Pulse wave velocity (PWV) was also estimated in Matlab (Mathworks, Natick, MA) to investigate the correlation with ES AWS.

\section{Results}

We observed a negative trend with no significant correlation between WSS (axial/circ) and ES AWS (Figure 1a, b). 4D flow derived WSS depend on fluid profile (i.e. laminar flow, peak flow and mean velocity) while MRE derived AWS is dependent on frequency of excitation, hence significant correlation fails to exist due to different principles being involved. Furthermore, very weak correlations were observed between ES AWS and PWV $(\mathrm{R} 2=0.17)$, ES AWS and mean velocity $(\mathrm{R} 2=0.1)$ and ES AWS and mean peak flow $\left(R^{2}=0.1\right)$ as shown in Figure 1c, d and e respectively. PWV and mean peak flow show a positive correlation with ES AWS while mean velocity shows a negative correlation.

\section{Conclusions}

From our results we can conclude that there is no correlation between ES AWS and WSS, however more studies are warranted.

\footnotetext{
Authors' details

'Department of Radiology, The Ohio State University, Columbus, OH, USA. ${ }^{2}$ Department of Radiology, Northwestern University, Chicago, IL, USA. ${ }^{3}$ Department of Internal Medicine Division of Cardiology, The Ohio State University, Columbus, OH, USA. ${ }^{4}$ Department of Electrical and Computer Engineering, The Ohio State University, Columbus, OH, USA. ${ }^{5}$ Department of Biomedical Engineering, The Ohio State University, Columbus, OH, USA.
} 


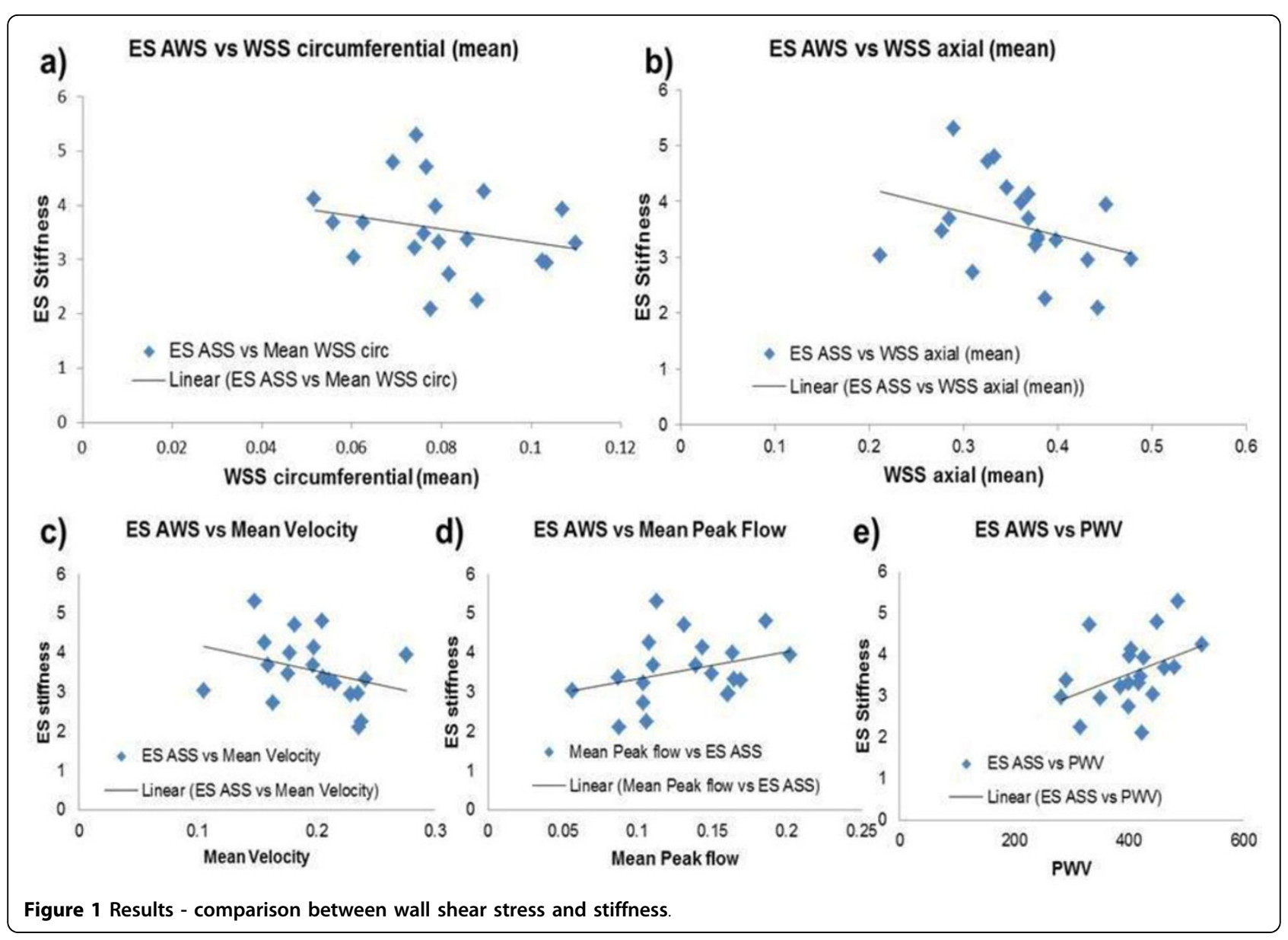

${ }^{6}$ Department of Biomedical Engineering, Northwestern University, Columbus, $\mathrm{OH}$, USA.

Published: 27 January 2016

doi:10.1186/1532-429X-18-S1-P360

Cite this article as: Illapani et al: Quantification and comparison of 4D Flow MRI derived wall shear stress and MRE derived wall shear stiffness of abdominal aorta. Journal of Cardiovascular Magnetic Resonance 201618 (Suppl 1):P360.

Submit your next manuscript to BioMed Central and take full advantage of:

- Convenient online submission

- Thorough peer review

- No space constraints or color figure charges

- Immediate publication on acceptance

- Inclusion in PubMed, CAS, Scopus and Google Scholar

- Research which is freely available for redistribution 